\title{
El examen clínico tiene una utilidad limitada para el diagnóstico de infección temprana por el Virus de la Inmunodeficiencia Humana
}

\author{
Clinical examination has limited utility to diagnosis early Human Immunodeficiency Virus infection
}

Wood E y col. JAMA (2014) 312, 278-285

\section{Objetivo}

Evaluar la precisión de los síntomas y signos en la identificación de la infección temprana por el Virus de la Inmunodeficiencia Humana (VIH) entre los pacientes adultos.

\section{Fuente de datos}

Se realizaron búsquedas en MEDLINE y EMBASE (1981-mayo de 2014) para artículos que investigaran síntomas y signos de la infección temprana por VIH en adultos, también se buscaron las listas de referencias de los artículos recuperados.

\section{Selección de estudios}

Se seleccionaron estudios originales que comparaban los síntomas y signos de pacientes con infección temprana por VIH, con individuos VIH negativos.

\section{Extracción de datos y síntesis}

Se extrajeron los datos y se utilizaron para calcular la sensibilidad, especificidad y cocientes de probabilidad o likelihood ratios $(\mathrm{CP})$. Se realizó un meta-análisis para calcular $\mathrm{CP}$ sumarios.

\section{Resultados}

De los 1.356 estudios, 16 estudios incluyeron datos elegibles para el meta-análisis. Se incluyeron un total de 24.745 pacientes y 1.253 casos de infección temprana por VIH. Ver tabla 1.
Tabla 1: Síntomas y signos asociados a aumento o disminución de la probabilidad de infección temprana por el Virus de la Inmunodeficiencia Humana

\begin{tabular}{c|c|c|c}
\multicolumn{2}{c|}{$\begin{array}{c}\text { Aumento de probabilidad de } \\
\text { infección temprana por VIH }\end{array}$} & \multicolumn{2}{c}{$\begin{array}{c}\text { Disminución de probabilidad } \\
\text { de infección temprana por VIH }\end{array}$} \\
\hline Síntoma & CP* (IC 95\%) & Síntoma & CP* (IC 95\%) \\
Úlceras genitales & $5,4(2,5 \mathrm{a} 12)$ & Ausencia de fiebre & $0,74(0,64 \mathrm{a} 0,84)$ \\
\hline Pérdida de peso & $4,7(2,1 \mathrm{a} 7,2)$ & $\begin{array}{c}\text { Ningún hallazgo } \\
\text { (combinado) }\end{array}$ & $0.47(0,38$ a 0,58$)$ \\
\hline Vómitos & $4,6(2,5 \mathrm{a} 8)$ & & \\
\hline Adenopatías & $4,6(1,3 \mathrm{a} 8)$ & & \\
\hline Adenopatía (signo) & $3,1(1 \mathrm{a} 5,2)$ & & \\
\hline
\end{tabular}

${ }^{*} \mathrm{CP}$ : cociente de probabilidad.

\section{Conclusiones}

La utilidad limitada del examen clínico para detectar o descartar la infección por VIH temprana destaca la importancia de las pruebas de rutina para la detección de infección por VIH entre los pacientes adultos.

Fuente de financiamiento: Estatal. Conflicto de interés: El Dr. Montaner informó que ha recibido becas y patrocinio de diferentes laboratorios.

\section{Comentario}

La infección temprana por VIH se define como el período de seis meses a partir del ingreso del virus al organismo ${ }^{1,2}$. La importancia de su detección radica en la disminución de la transmisión viral a los contactos del paciente, la disminución de las conductas potencialmente transmisoras del virus y de otras enfermedades, ofrece una oportunidad de tratamiento temprano y reduce la transmisión vertical. El tratamiento temprano en comparación al instaurado luego de la aparición de enfermedades relacionadas a la inmunosupresión resulta en una disminución de la morbimortalidad ${ }^{3-8}$.

Durante el período de infección temprana, más de la mitad de los pacientes desarrollan un síndrome retroviral agudo consistente en un conjunto variable de síntomas, similar a otras enfermedades virales: fiebre, pérdida de peso, mioartralgias, náuseas, faringitis, úlceras orales, linfadenopatía y rash, entre otros $^{9,10}$. Los síntomas que se relacionaron con mayor probabilidad de estar cursando infección temprana por HIV fueron pérdida de peso, úlceras genitales, vómitos y presencia de ganglios linfáticos aumentados de tamaño. La ausencia de fiebre reciente aleja la posibilidad de que el paciente esté cursando una infección temprana por VIH. El signo que se relacionó con mayor probabilidad de tener infección temprana por VIH fue la presencia de linfadenopatía.

Las limitaciones de este meta-análisis radican en que sus conclusiones son válidas siempre y cuando se conozca la prevalencia de la infección por VIH en la población, dato no siempre disponible.

\section{Conclusiones del comentador}

Este artículo reafirma los fundamentos de la indicación de rastreo universal de $\mathrm{VIH}$ en la población adulta para mejorar la expectativa de vida de los pacientes infectados y disminuir la transmisión. Si bien el examen físico demostró tener poca utilidad para sospechar la infección temprana, los médicos de atención primaria deben estar atentos a los mismos ya que pueden mejorar la salud del paciente que los consulta, así como la de la población general.

María Adela Aguirre [ (Servicio de Clínica Médica del Hospital Italiano de Buenos Aires. Instituto Universitario del Hospital Italiano de Buenos Aires. Grupo de estudio de la Amiloidosis. adela.aguirre@ hospitalitaliano.org.ar) ]

Aguirre MA. El examen clínico tiene una utilidad limitada para el diagnóstico de infección temprana por el Virus de la Inmunodeficiencia Humana. Evid Act Pract Amb. 2015;18(3):89. Jul_Sep. Comentado de: Wood E, y col. Does This Adult Patient Have Early HIV Infection? The Rational Clinical Examination Systematic Review. JAMA. 2014;312 (3):278-285. PMID: 25027143

\section{Referencias bibliográficas}

1. Tindall B, y col. Characterization of the acute clinical illness associated with human immunodeficiency virus infection. Arch Intern Med. 1988;148(4):945

2. Schacker T, y col. Clinical and epidemiologic features of primary HIV infection. Ann Intern Med. 1996;125(4):257.

3. Marks G, y col. Estimating sexual transmission of HIV from persons aware and unaware that they are infected with the virus in the USA. AIDS. 2006:20(10):1447-1450. 